Egypt. Acad. J. Biolog. Sci., 4 (1): 49- 59 (2012)

Email: egyptianacademic@yahoo.com

Received: 1 / 12 / 2012
F. Toxicology \&Pest control

ISSN: 2090 - 0791

www.eajbs.eg.net

\title{
Effect of three insect growth regulators (Chlorfluazuron, Tebofenozoid and pyriproxyfen) on fecundity of $S$. littoralis, histopathological and some biochemical aspects of moth ovary.
}

\author{
Aziza E. Abdel-Aal \\ Plant Protection Research Institute, A.R.C., Dokki-Giza, Egypt
}

\begin{abstract}
The insecticidal and biological effects of three insect growth regulator (chlorfluazuron, Tebofenozoid and pyriproxyfen) were evaluated on $4^{\text {th }}$ instar larvae of Spodoptera littoralis (Boisd.) (Lepidoptera: Noctuidae). Based on the $\mathrm{LC}_{50}$ values Chorofluazuron is the more toxic to $S$. littoralis than that of the two other compounds. Female longevity, fecundity and fertility were significantly reduced at all treatments compared to control. Furthermore, different levels of significant changes in the total protein, carbohydrate contents of the female ovaries pre-treated as $4^{\text {th }}$ instar larvae by $\mathrm{LC}_{50}$ of used IGRs were recorded. Moreover, different abnormal histological structures of ovary were noticed.
\end{abstract}

Keywords: Insect growth regulators (IGR's), Toxicity, $\mathrm{LC}_{50}$, Spodoptera littoralis, biological, biochemical and histological aspects.

\section{INTRODUCTION}

The extensive use of insecticides to control Spodoptera littoralis (Boisd.) larvae has led to its resistance to various classes of insecticides (Tabashink et al., 1987) residual toxicity and environmental pollution (Frank et al., 1990) and negative effects on non-target organisms (Franz, 1974) .A new approach to insect pest control is the use of substances that adversely affect insect growth and development. These substances are classified as insect hormone mimics or insect growth regulators (IGRs) owing to their effects on certain physiological regulatory processes essential to the normal development of insects or their progeny. They are quite selective in their mode of action and potentially act only on target species .The action of IGRs, however, should not be confused with other synthetic insecticides, such as organophosphates and carbamates, since these chemicals interfere with other physiological processes but do not regulate the development of normal insects Also these compounds causes histological aberration of the mid gut of insects Thabit et al. (2010). There are three types of IGRs, each of which has a different mode of action:

1- Chitin synthesis inhibitors: These prevent the formation of chitin, a carbohydrate that is an important structural component of the insect's exoskeleton. When treated with one of these compounds, the insect grows normally until the time to molt. When the insect molts, the exoskeleton is not properly formed and it dies. Death may be quick, but in some insects it may take several days. As well as disrupting molting, chitin synthesis inhibitors can kill eggs by disrupting the normal development of the embryo e.g. Chlorofluazuron.

2- Anti jovenoid: This group of compounds induces a premature and lethal larval moult by direct stimulation of ecdysteroid receptors, especially in larval Lepidoptera e.g. (tebofenozoid).

3- Juvenile hormone analogue: When applied to an insect, these abnormal 
sources of juvenilizing agent can have striking consequences e.g. pyriproxyfen.

The aim of the work to evaluate three insect growth regulators (chlorfluazuron, Tebofenozoid and pyriproxyfen) for controlling $S$. littoralis larvae. This can be attained by determining their possible larvicidal effects as well as determining their possible latent effects on certain biological aspects (adult longevity, fecundity and fertility) As well as latent effect on histopathological and biochemical studies of the ovaries.

\section{MATERIALS AND METHODS Insect Rearing Technique:}

Egg masses of the cotton leafworm, Spodoptera littoralis were obtained from Plant Protection Research Institute without any insecticidal pressure. Newly hatched larvae were transferred to clean glass jars covered with muslin held in position with rubber bands. They were fed on castor bean leaves, Ricinus communis, L. at $27 \pm 2$ ${ }^{\mathrm{O}} \mathrm{C}$ and $65 \pm 5 \%$ RH El-Defrawi et al. (1964).

\section{Insect growth regulators:}

Two insect growth regulators (IGRs) obtained from Sumitomo Chemical Co., Ltd. were used during the present work. One of which are chitin synthesis inhibitors Chlorfluazuron (IKI$7899,10 \%$ EC) and the second is a juvenile hormone analogue Pyriproxyfen (Admiral, $10 \%$ EC). The third is Tebufenozide (Mimic ${ }^{\circledR}$, Confirm ${ }^{\circledR}, 24 \%$ E.C.) obtained from Rohm \& Haas Co.

Relative susceptibility of $4^{\text {th }}$ instars of S. littoralis to tested IGRs:

From the maintained insect culture, the $4^{\text {th }}$ instar larvae were obtained. Then, they feed on castor oil leaves treated with different concentrations of the tested compounds. The percentages of mortality in untreated and treated larvae were recorded and calculated per each concentration, corrected using Abbott's formula (1925) if necessary. The corrected percentage mortality of the compound was statistically computed according to Finney (1971) to determine the $\mathrm{LC}_{50}$, $\mathrm{LC}_{90}$ and slope values of the tested compounds.

\section{The latent effect on adult:-}

The pupae resulted from fourth instars treated with $\mathrm{LC}_{50}$ of all toxicants were sexed and then placed in pairs in the glass globes in one of the following combinations : treated male $\mathrm{x}$ treated female, treated male x untreated female and treated female $\mathrm{x}$ untreated male, in addition to untreated male $\mathrm{x}$ untreated female as control ,in these cases the adults were confined in a glass jar containing a cotton pad soaked with $20 \%$ sugar solution as a food and stripes of paper as an ovipositional substrate. The eggs deposited per each mated were collected daily and counted to give an estimate of fecundity and the deterrent index was calculated according to Lundgren (1975) as:

\section{Deterrent index $=\{(A-B) /(A+B)\} x$}

\section{0}

Where A: the total number of eggs per female in control.

B: the total number of eggs per female in treatment.

The percentage of egg hatch or fertility was determined and subsequently, the percentage of sterility was calculated according to Crystal $(1968)$ as sterility $=(1-\mathrm{fh}) \times 100$, where " $\mathrm{f}$ " is the corrected decimal fractions of the percentage of fecundity. " $\mathrm{h} "$ is the corrected decimal fractions of the percentage of fertility. The corrected percentage of either fecundity or fertility was then calculated as (A/ B) x100, where $\mathrm{A}$ and $\mathrm{B}$ are the treatment and control effect of either fecundity or fertility, respectively.

\section{Histopathologicl studies of the ovaries:-}

The surviving virgin treated and untreated females were dissected in 
ringer's solution on the first day of emergence. The ovaries were fixed in carnoy's solution, embedded in paraffin wax, and stained with heamatoxylin and aeosin.

Biochemical effects on the females ovaries:-

The effect on the ovaries of virgin females obtained from larval treatment with $\mathrm{LC}_{50}$ values of the three tested IGRs was studied .The total protein, carbohydrate and lipid of the ovaries of both treated and normal females were determined according to Lowery et al., (1951), Singh, Sinha (1977), Baronos and Blackstck (1973), respectively.

\section{RESULTS AND DISCUSSION Susceptibility of $4^{\text {th }}$ instars of $S$. littoralis to tested IGRs:}

Table (1) shows the susceptibility of the $4^{\text {th }}$ instars of S.littoralis towards the tested IGRs. Based on $\mathrm{LC}_{50}$ values the toxicity of the IGRs can be arranged in a descending order as follows: chlorfluazuron $>$ tebofenozoid $>$ pyriproxyfen. The toxicity index indicates that chlorfluazuron (standard IGR) was about 1.8 and 4194 times as toxic as tebofenozoid and pyriproxyfen, respectively. The obtained results are confirmed with those obtained by Haga et al., (1984) who reported that Chlorfluazuron is very toxic to insects because it metabolizes slowly inside the insect body. The toxicity of Chlorfluazuron against $S$. littoralis larvae was somewhat similar to that obtained by Farag (2001), Abdel Aal (2006) and on A. ipsilon (Shurab et al., 1999). Also the toxicity of five insect growth regulators on $4^{\text {th }}$ instar of $S$. littoralis was recorded by Abdel-aal et al., (2009).

Table 1: Susceptibility of $S$. littoralis $4^{\text {th }}$ instar larvae to chlorfluazuron,tebofenozoid and pyriproxyfen.

\begin{tabular}{|c|c|c|c|c|c|c|}
\hline \multirow{2}{*}{ IGR's } & \multirow{2}{*}{$\begin{array}{c}\mathrm{LC}_{50} \\
\mathrm{ppm}\end{array}$} & \multicolumn{2}{|c|}{$95 \%$ Fiducial limits } & \multirow{2}{*}{ Slope+ S.E. } & \multirow{2}{*}{$\chi^{2}$ (d.f.) } & $\begin{array}{c}\text { Toxicity } \\
\text { index }\end{array}$ \\
\cline { 3 - 4 } & & Lower & Upper & & & \\
\hline Chlorfluazuron & 0.166 & 0.155 & 0.244 & $1.65 \pm 0.3$ & 1.290 & 1.00 \\
\hline Tebofenozoid & 0.353 & 0.176 & 0.534 & $1.22 \pm 0.3$ & 0.162 & 0.55 \\
\hline Pyriproxyfen & 756.19 & 464.60 & 1173.900 & $1.14 \pm 0.26$ & 1.220 & $2.38 \times 10^{-4}$ \\
\hline
\end{tabular}

\section{The latent effect on adult:-}

Effect on adult emergence: The result in table (2) indicated that the adult emergence $\%$ of moth pretreated as $4^{\text {th }}$ instar by tested IGRs reduced by 16 , 6.5 and $2 \%$ as treated with chlorofluazuron, tebufenozoid and pyriproxyfen respectively. The decrease in percentage of adult emergence may be due to the fact that toxin block the maturation of imaginal discs which are primordial for adult integumentary structures in endopterygote insects (Schneidermann 1972 and Suh et al., 2000).

Table 2: Effect of Chlorfluazuron, Tebfenozoid and Pyryproxyfen on total oviposition periods and mean adult longevity of $S$ littoralis.

\begin{tabular}{|c|c|c|c|c|c|}
\hline \multirow{2}{*}{ Compounds } & \multicolumn{2}{|c|}{ Total oviposition periods (days) } & \multirow{2}{*}{$\begin{array}{c}\text { Adult } \\
\text { emergence } \%\end{array}$} & $\begin{array}{c}\text { Mean of adult life } \\
\text { span (days } \pm \text { S.E.) }\end{array}$ \\
\cline { 2 - 4 } & pre & Ovi & Post & $84(16)$ & $9.6 \pm 0.28^{* * *}$ \\
\hline Chlorfluazuron & $2.2 \pm 0.10$ & $3.9 \pm 0.95$ & $3.3 \pm 0.31$ & 8.951 .5 & $11.00^{*} \pm 0.28$ \\
\hline Tebofenozoid & $2.1 \pm 0.32$ & $4 \pm 0.62$ & $4.9 \pm 0.51$ & $93.5(6.5)$ & $14.5^{* *} \pm 0.19$ \\
\hline Pyriproxyfen & $3.2 \pm 0.4$ & $5.3 \pm 1.2$ & $6 \pm 1.42$ & $98(2)$ & $12.3 \pm 0.1$ \\
\hline Control & $2.3 \pm 0.21$ & $4.6 \pm 0.14$ & $5.4 \pm 1.21$ & 100 & \\
\hline
\end{tabular}

Number between bracts is reduction in adult emergence

The latent effect on adult fecundity and fertility:
Table (3) shows latent effect on the fecundity of $S$. littoralis female moths 
surviving treatment of as $4^{\text {th }}$ instars with tested IGRs. The results obtained show that the lowest number of eggs laid per female and consequently the highest deterrent index were obtained for treated females mated with treated males, followed by treated females mated with normal males, as compared to control. On the other hand, the highest number of eggs lay per female and consequently the lowest deterrent indexes were occurred when the males were the treated sex only. This may indicate that the females were more sensitive to toxicants than the males. The result indicated that chlorfluazuron was the most effective compound on fecundity of S.littoralis, while pyriproxyfen recorded the lowest one.

Table 3: Reproductive potential of $S$. littoralis (Boisd.) moths treated as $4^{\text {th }}$ instar larvae with $\mathrm{LC}_{50}$ of Chlorfluazuron, Tebfenozoid and Pyryproxyfen.

\begin{tabular}{|c|c|c|c|c|c|c|}
\hline \multirow[b]{3}{*}{ IGRs } & \multicolumn{6}{|c|}{ Mating combination } \\
\hline & \multicolumn{2}{|c|}{$\mathrm{T}_{+} \mathrm{x} \mathrm{T}_{0}^{\hat{1}}$} & \multicolumn{2}{|c|}{$\mathrm{T} 9 \times \mathrm{N}$} & \multicolumn{2}{|c|}{$\mathrm{N} q \mathrm{x} \mathrm{T} \sigma^{\wedge}$} \\
\hline & $\begin{array}{l}\text { No. of egg } \\
/ q \pm \text { S.E. }\end{array}$ & $\begin{array}{c}\text { Oviposition } \\
\text { Deterrent } \\
\text { index } \% \\
\end{array}$ & $\begin{array}{l}\text { No. of egg } \\
/ q \pm \text { S.E. }\end{array}$ & $\begin{array}{c}\text { Oviposition } \\
\text { Deterrent } \\
\text { index } \% \\
\end{array}$ & $\begin{array}{l}\text { No. of egg } \\
/ q \pm \text { S. E. }\end{array}$ & $\begin{array}{c}\text { Oviposition } \\
\text { deterrent } \\
\text { index } \% \\
\end{array}$ \\
\hline Chlorfluazuron & $151 * * * \pm 4.4$ & 46.0 & $170 * * * \pm 5.8$ & 41.0 & $180 * * * \pm 5.8$ & 38.7 \\
\hline Tebofenozoid & $221 * * \pm 6.6$ & 29.7 & $226 * * * \pm 7.2$ & 28.0 & $251 * * * \pm 7.3$ & 23.7 \\
\hline Pyriproxyfen & $305 * * \pm 6.6$ & 20.5 & $380 * * \pm 2.8$ & 18.6 & $390.7 * \pm 5.8$ & 14.3 \\
\hline Control & $408 \pm 13.0$ & - & - & - & - & - \\
\hline
\end{tabular}

* Significant at $\mathrm{P}<0.05 . \quad * *$ Highly significant at $\mathrm{P}<0.001 . * * *$ Very highly significant at $\mathrm{P}<0.001$

Table (4) shows that in all the mating combinations the egg-hatch percent was decreased, as compared to control. This reduction was much obvious in case of chlorfluazuron treatment, followed by tebofenozoid and pyriproxyfen treatments. This is also true for the percentage of sterility. The fertility followed the same pattern as that of fecundity, i.e., the lowest egg-hatch was obtained in the mating combination containing treated females.

Table 4: Effect of $\mathrm{LC}_{50}$ of Chlorfluazuron Tebfenozoid and Pyryproxyfen on fertility of S. littoralis.

\begin{tabular}{|c|c|c|c|c|c|c|}
\hline \multirow{3}{*}{ IGRs } & \multicolumn{6}{|c|}{ Mating combination } \\
\hline & \multicolumn{2}{|c|}{$\mathrm{T} \propto 9 \times \mathrm{T} \circlearrowleft$} & \multicolumn{2}{|c|}{$\mathrm{T} \propto \mathrm{x} \mathrm{N} \sigma^{\lambda}$} & \multicolumn{2}{|c|}{$\mathrm{N} \odot \mathrm{x} \mathrm{T} \sigma^{\lambda}$} \\
\hline & \begin{tabular}{|c|} 
Egg \\
hatchability $\%$
\end{tabular} & Sterility \% & $\begin{array}{c}\text { Egg } \\
\text { Hatchability \% }\end{array}$ & Sterility \% & $\begin{array}{c}\text { Egg } \\
\text { Hatchability } \%\end{array}$ & Sterility \% \\
\hline Chlorfluazuron & 65.0 & 74.0 & 66.0 & 70.0 & 71.0 & 66.0 \\
\hline Tebofenozoid & 65.0 & 64.0 & 68.0 & 59.0 & 73.0 & 55.1 \\
\hline Pyriproxyfen & 78.0 & 47.4 & 82.0 & 38.7 & 94.0 & 23.0 \\
\hline Control & 91.8 & - & - & - & - & \\
\hline
\end{tabular}

The suppression of egg production per treated female obtained in this study may be due, in part, to interference of the tested IGRs with oogenesis. Reduction in the percentage of egg-hatch obtained in the present study may be attributed to sterilization of either eggs and or/sperms; or may be due to inability of the sperms to be transferred to females during copulation (Ismail, 1980). Moursy and Bartlett (1991-1992) reported that the JHA, pyriproxyfen decreased the number of spermatophores transferred to $P$. gossypiella females. Riddiford (1970) demonstrated that in endopterygote insects the juvenoids may cause female sterility when applied at a certain stage of oocyte development. Taher and Cutkomp (1983) suggested that the sterility of females seems to be attributed chiefly to a delay or reduction of ova giving same opportunities not for 
retention but for possible re sorption of eggs in ovaries. They also added that although the cause for the delay is not known, it could be due, in part, to a lower metabolic rate.

\section{Histological Effects:}

In normal female moths Fig (1), the four convoluted ovarioles in each ovary are "8" polytrophic ovarioles and each ovariole consists of a chain of developing egg follicles. Histologically each follicle Fig. (2) consists of a growing oocyte accompanied interiorly by a few number of nurse cells. The oocyte is surrounded by somewhat columnar or cuboidal follicular epithelium, while the nurse cells are surrounded by squamous follicular epithelium.

Fig. (3) showed the effect of Chlorofluazuron treatment on the female ovary. The histological abnormalities, Fig. (4) were in the form of oocytes shrinkage which leaving space around it and other were semi absorbed. The follicular epithelium became thin and slightly vacuolated.

Figs. (5\& 6) showed that Tebofenozoid treatment because slight clumping of chromatin materials leaving space near the epithelial cells, absence of some nurse cells and also the oocytes were semi absorbed.

\section{Biochemical aspects on the ovaries:-}

From data in table (5) it is clear that chlorofluazuron, tebufenozoid and pyriproxyfen decreased the biothynthesis of total protein, carbohydrate and lipid contents of the overioles of $S$. littoralis females as compared wih normal females.

Table5: Effect of Chlorfluazuron, Tebfenozoid and Pyryproxyfen on total protein, Carbohydrat and lipid contents in the ovarioles of $S$. littoralis post $48 \mathrm{~h}$ feeding $4^{\text {th }}$ instar larvae

\begin{tabular}{|c|c|c|c|c|}
\hline Compound & $\mathbf{L C}_{50}$ & $\begin{array}{l}\text { Totalprotein } \\
(\mathrm{mg} / \mathrm{g}) \text { fresh } \\
\text { tissues } \pm \text { S.E. } \\
\end{array}$ & $\begin{array}{c}\text { Total carbohydrat } \\
\text { (mg/g) fresh } \\
\text { Tissues +S.E. }\end{array}$ & $\begin{array}{c}\text { Total lipid } \\
(\mathrm{mg} / \mathrm{g}) \text { fresh } \\
\text { tissues+S.E. }\end{array}$ \\
\hline Chlorfluazuron & 0.166 & $23.6 *+.8$ & $46.2 * * *+0.9$ & $88.3 * * *+0.7$ \\
\hline Tebofenozoid & 0.353 & $21.6 * *+0.5$ & $36.1 * * * \pm 0.6$ & $55.2 * * *+1.3$ \\
\hline Pyriproxyfen & 756.19 & $30.2^{\mathrm{ns}} \pm 0.12$ & $82.3^{\mathrm{ns}} \pm 0.4$ & $92.5^{\mathrm{ns}} \pm 0.5$ \\
\hline Control & 0.0 & $33.7+0.2$ & $89.9+1.2$ & $98.3+0.9$ \\
\hline
\end{tabular}

Decreased total ovarian protien of S. littoralis following treatment is similar to the the results of soltani and Mazouni(1992) that diflubenzuron reduced the total protein per ovary in Cydia Pomonella Also the same result recorded by shurab et al.,(1999) that chlorofluazuron and flufenoxuron reduced the total (protein, carbohydrate and lipid ) in ovary in A. ipsilon female. The decreaseed ovarian protein obtained in this study may be due to decreased larval haemolyph, protein as a result of treatment .This suggestion is confirmed by the data of many workers that larval haemlymph protein contributed in deveoping ova in lepidoptera (kong and kim, (1988). Gglucose, obtained from the haemolymph is utilized by the oocyte for the synthesis of glycogen at the periplasma (Ramamurty, 1968). According to these findings decreased in total carbohydrate in the ovariole of $S$. littoralis treated with Chlorofluazuron and Tebofenozoid may be accounted for the histological damages of both the oocyte and follicular epithelium caused by these two compounds as shown in this study. Decreased in total lipid in the overioles of $S$. littoralis treated with Chlorofluazuron and Tebofenozoid may be interperted by the damage of both the nurse cells and follicular epithelium as shown in this study, where these tissues 
were found to contributed in lipid deposition to the devolping oocyte (Tiripthi and kumar, 1982).

Moreover, it is probably that these compounds affected the fat bodies of $S$. littoralis during the period following larval treatment with them which ultimately led to decreased lipid deposition in the devolping oocyte. In general, the development of oocytes in most insects is under hormonal control and involves the neurosecretory cells and corpora allata. The histological aberration in this study are agree with Abdel Aal and Abdel Wahab (2007) when he studied the Ovicidal effects of lufenuron on the cotton leafworm, Spodoptera littoralis.

\section{REFERENCES}

Abbott, W. S. (1925). A method for computing the effectiveness of an insecticide. J. Econ. Entomol., 18: 265-267.

Abdel - Aal, Aziza. E and Abdel Wahab, I. S. (2007). Ovicidal and latent effects of lufenuron and spinosad on the cotton leafworm, Spodoptera littoralis (Boisd.) J. Agric.Sci. Mansoura Univ., 32 (6): 48-06.

Baronos, H. and Blackstock, J. (1973). Estimation of lipids in marine animals and tissue: Detailed investigations of the sulphophosphovanillin method for total lipids. J. Exp. Mar. Biol. Ecol., 12: 103-118.

Crystal, M. M. (1968): Sexual sterilization of screw-worm by $\mathrm{N}$ tetramethylene bis (1azidridine)arboxoxamide:influence of route administration. J. Econ. Entomol. 16, 134-139.

El- Sheikh. .T.A; Abdel-aal Aziza, E. and Farag , A.M. (2009). Effect of Spinosad and Tebufenozide on some biological, biochemical and immunological parameters of cotton leafworm, Spodoptera littoralis
(Boisd.) Egypt. J. Agric.Res., 87(2): 73-90.

El-Defrawi, M. E.; Toppozada, A.; Mansour, N. and Zeid, M. (1964). Toxicological studies on the Egyptian cotton leafworm, Prodenia littura (L.). I.Susceptibility of different larval instars of Prodenia to insecticides. J. Econ. Entomol., 57: 591-593.

Finney, D. J. (1971). In "Probit analysis". $3^{\text {rd }}$ ed., Cambridge Univ. Press, London, U.K.

Ismail, I. E. (1980). Physiological studies on the effect of juvenile hormone analogues upon the cotton leafworm, Spodoptera littoralis (Boisd.). Ph. D. Thesis, Cairo Univ., Egypt.

Kong, C. and kim ,H. R. (1988). An immunological study of storage protein in Hyphantria cunea Durry. Korean J. Entomol., 18:169-175.

Lowry, O. H.; Rosebrough, N. J.; Farr, A. L. and Randall, R. J. (1951). Protein measurement with folin phenol reagent. J. Biol. Chem., 193: 265-275.

Lundgren, L. (1975). Natural plant chemicals acting as oviposition deterrents on cabbage butterflies, Pieris brassicae (L.), P. rapa (L.) and $P$. napi (L.). Zoll. Ser., 4: 250258.

Moursy, E. B. and Bartlett, A. C. (19911992). Effect of "pyriproxyfen" as juvenile hormone analogue on the reproductive potentiality of the pink bollworm Pectinophora gossypiella (Saund.). Bull. ent. Soc. Egypt, Econ. Ser., 10:191-197.

Riddiford, L. M. (1970). Prevention of metamorphosis by exposure of insect to juvenile hormone analogue. Science, N. Y., 167: 287-288.

Schneidermann, H. A. (1972). Insect hormone and insect control. In: Insect Juvenile Hormone, Chemistry and Action. J.J. Menn and M. Beroza (Eds.), Academic Press, New York, London: 3-27. 
Shaurub, E. H.; Emara, S. A.; Zohdy, N. Z. and Abdel-Aal, A. E. (1999). Effect of four insect growth regulators on the black cutworm, Agrotis ipsilon (Hufn.) (Lepidoptera: Noctuidae). The $2^{\text {nd }}$ Int. Conf. of Pest Control, Mansoura, Egypt: 773-776.

Singh, N. B. and Sinha, R. N. (1977). Carbohydrates, lipids and proteins in the developmental stages of Sitophilus oryzae and S. granarius (Coleoptera: Curculionidae). Annu. Entomol. Soc. Amer., 70: 107-111.

Soltani ,N.and Mazouni,N 1992: Diflubenzuron and oogensis in the codlind moth,Cydia pomonella L. pestic. Sci., 34: 257 -261.

Suh, C. P. C.; Orr, D. B. and Van Duyn, J. W. (2000). Effect of insecticides on Trichogramma exiguum (Hymenoptera: Trichogrammatidae) preimaginal development and adult survival. J. Econ. Entomol., 93: 577583.

Taher, M. and Cutkomp, L. K. (1983). Effect of sublethal doses of DDT and three other insecticides on Tribolium confusum. J. Stored Prod. Res., 19: 43-50.

Thabit, A.; El Salamouny, S.; Abdel-Aal, A. E.; El-Sheikh, M. A. K. and Elnagar, S. (2010). Enhancement of Spodoptera littoralis suscebtability to nucleopolyhedrovirus (splimnpv) combined with insect growth regulators (igrs) .Bull. Fac. Agric., Cairo Univ., 61: 92-96.

Tripathi, C.P.M. and Kumar, A. (1982). Effect of thiourea on lipid synthesis in the ovarioles of flesh fly, Sarcophaga ruficomis (fabr) (Diptera- Sarcophagidae) Entomol., 7:181-185. 


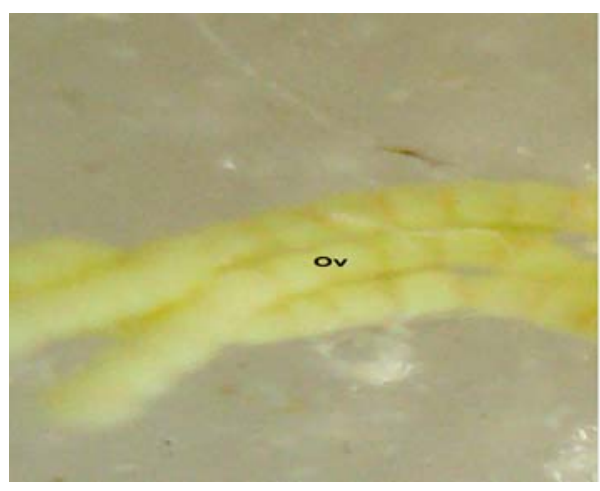

Fig. 1: Normal ovarioles of healthy female moth of S.littoralis Showing the shape of Oocyte. OV Ovariole.

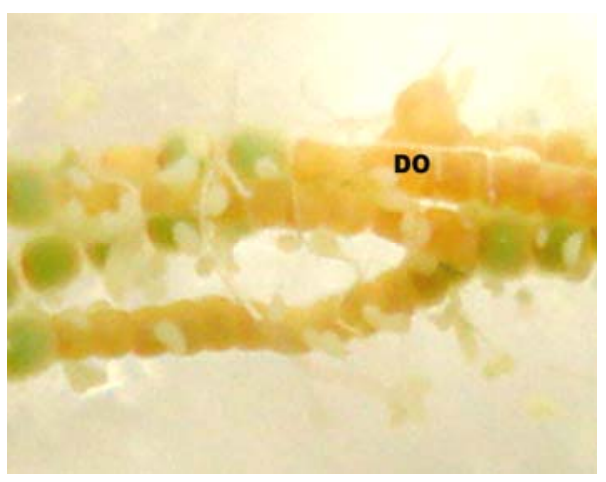

Fig. 3: Ovaries of female moths resulted from treated $4^{\text {th }}$ instar larvae of $S$. littoralis with Chlorofluazuoron showing the shape of degenerated Oocyte.

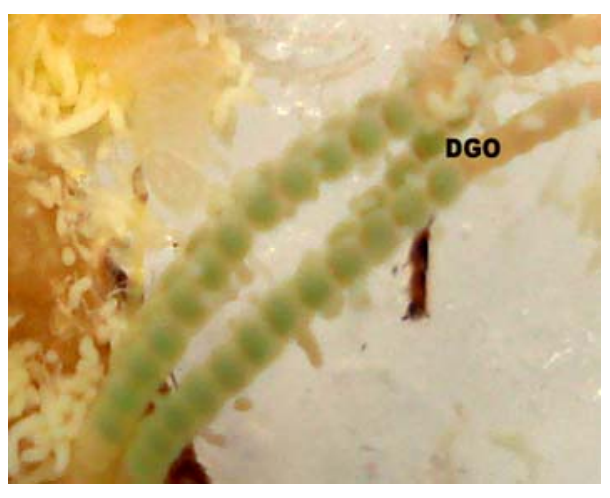

Fig. 5: Ovaries of female moths resulted from treated $4^{\text {th }}$ instar larvae of $S$. littoralis with Tebofenozoid showing the shape of degenerated Oocyte.

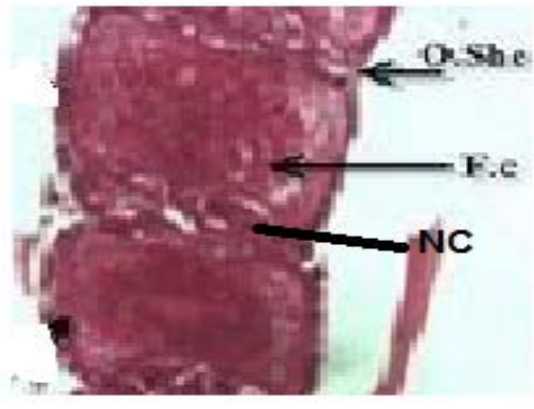

Fig. 2: Longitudinal sections in ovariole of normal $S$. littoralis adult (10X): nurse cell,F C: follicle cell, O.she: oocyte sheath.

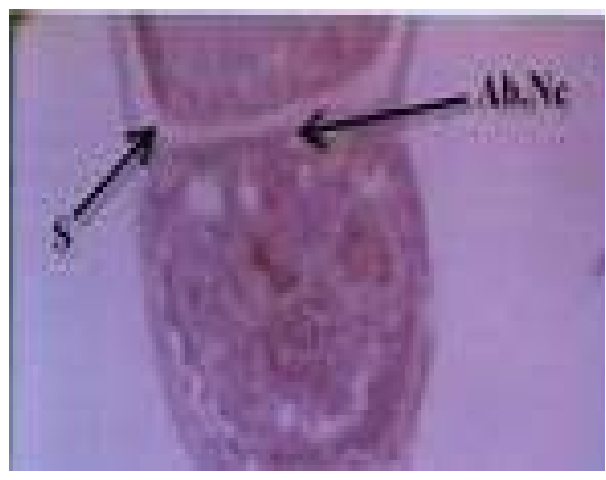

Fig. 4: L.S through female ovarioles of S. littoralis moth pretreated as $4^{\text {th }}$ instar with $\mathrm{LC}_{50}$ of Tebofenozoid. Ab.NC: abnormal nurs cell.

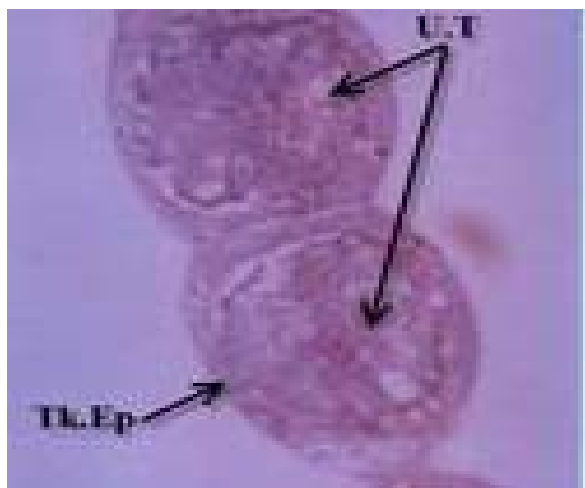

Fig. 6: L.S through female ovarioles of S. littoralis following feeding of $4^{\text {th }}$ instars larvae for $48 \mathrm{~h}$ on castor oil leaves treated with $\mathrm{LC}_{50}$ Chlorofluazuron. 


\section{ARABIC SUMMARY}

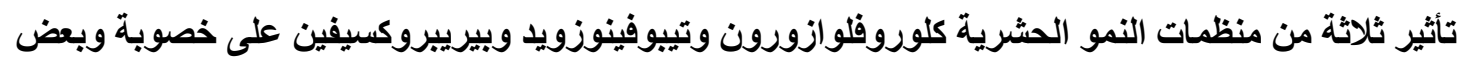

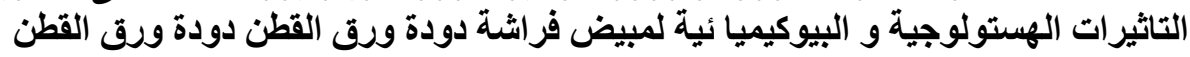

$$
\text { معهد بحوث وقاية النباتاتــ مركز البحوث الزبد العال اعية ـ الدقىـ جيزة. }
$$

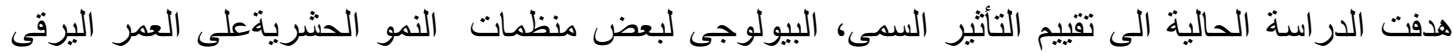

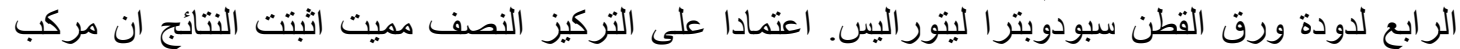

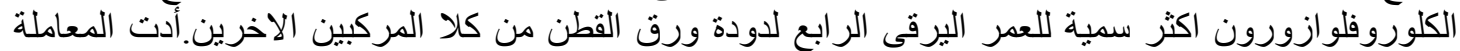

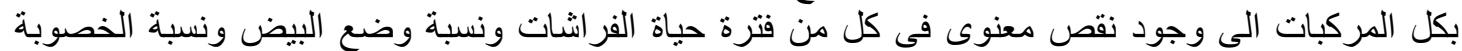

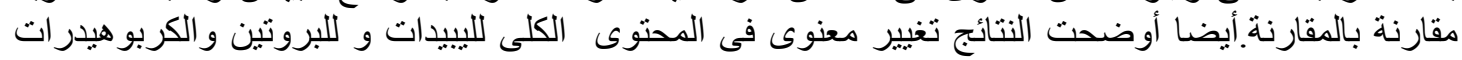

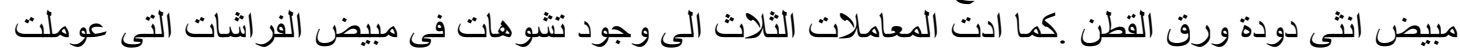

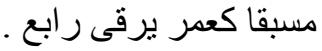

